PREPARED FOR THE U.S. DEPARTMENT OF ENERGY, UNDER CONTRACT DE-AC02-76CH03073

PPPL-3656

PPPL-3656

UC-70

Status of the Experimental Physics and Industrial Control System at NSTX

by

P. Sichta and J. Dong

January 2002

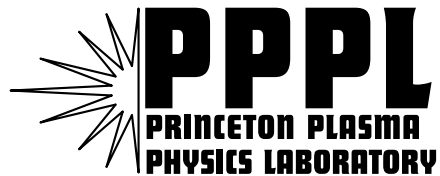

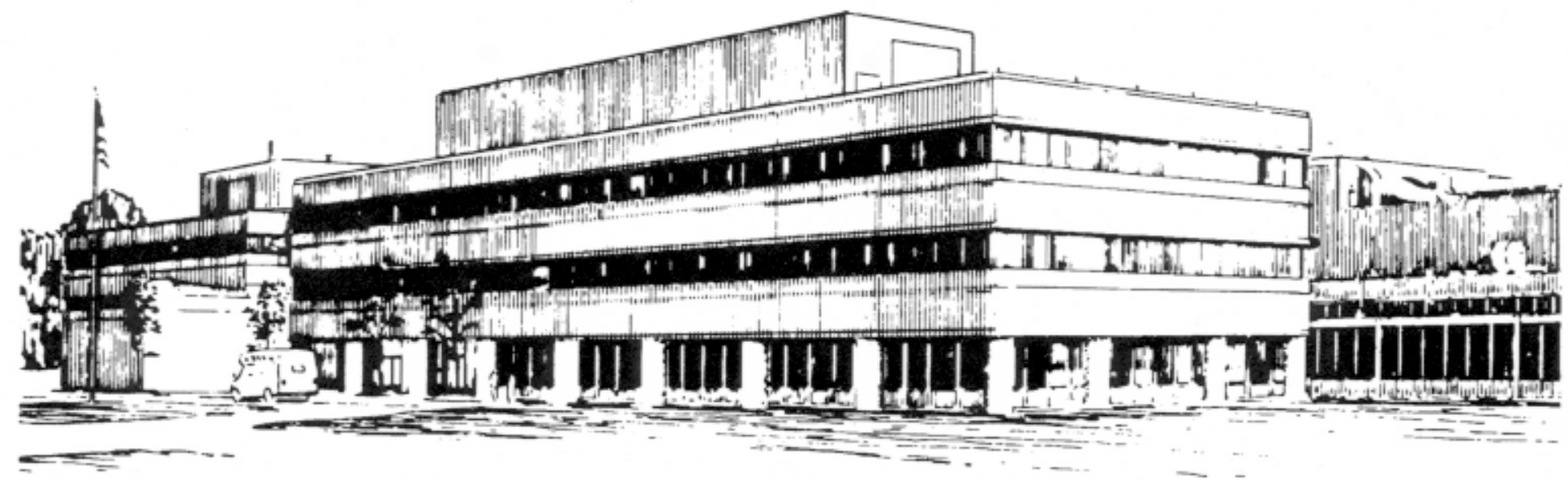

PRINCETON PLASMA PHYSICS LABORATORY PRINCETON UNIVERSITY, PRINCETON, NEW JERSEY 


\section{PPPL Reports Disclaimer}

This report was prepared as an account of work sponsored by an agency of the United States Government. Neither the United States Government nor any agency thereof, nor any of their employees, makes any warranty, express or implied, or assumes any legal liability or responsibility for the accuracy, completeness, or usefulness of any information, apparatus, product, or process disclosed, or represents that its use would not infringe privately owned rights. Reference herein to any specific commercial product, process, or service by trade name, trademark, manufacturer, or otherwise, does not necessarily constitute or imply its endorsement, recommendation, or favoring by the United States Government or any agency thereof. The views and opinions of authors expressed herein do not necessarily state or reflect those of the United States Government or any agency thereof.

\section{Availability}

This report is posted on the U.S. Department of Energy's Princeton Plasma Physics Laboratory Publications and Reports web site in Fiscal Year 2002. The home page for PPPL Reports and Publications is: http://www.pppl.gov/pub_report/

DOE and DOE Contractors can obtain copies of this report from:

U.S. Department of Energy

Office of Scientific and Technical Information

DOE Technical Information Services (DTIS)

P.O. Box 62

Oak Ridge, TN 37831

Telephone: (865) 576-8401

Fax: (865) 576-5728

Email: reports@adonis.osti.gov

This report is available to the general public from:

National Technical Information Service

U.S. Department of Commerce

5285 Port Royal Road

Springfield, VA 22161

Telephone: 1-800-553-6847 or

(703) 605-6000

Fax: (703) 321-8547

Internet: http://www.ntis.gov/ordering.htm 


\title{
Status of the Experimental Physics and Industrial Control System at NSTX *
}

\author{
P. Sichta, J. Dong \\ Princeton Plasma Physics Laboratory, P.O. Box 451, Princeton, New Jersey 08543
}

\begin{abstract}
The NSTX achieved first plasma in 1999. The Experimental Physics and Industrial Control System (EPICS) is used to provide data-integration services for monitoring and control of all NSTX engineering subsystems. EPICS is a set of software initially developed at US DOE laboratories. It is currently used and maintained through a global collaboration of hundreds of scientists and engineers. This paper will relate some of our experiences using and supporting the EPICS software. Topics include reliability and maintainability, lessons learned, recently added engineering subsystems, new EPICS software tools, and a review of our first EPICS software upgrade. Steps to modernize the technical infrastructure of EPICS to ensure effective support for NSTX will also be described.
\end{abstract}

\section{INTRODUCTION}

The EPICS-based NSTX Central Instrumentation and Control system (CI\&C) [1] has been in operation for more than two years. A simplified diagram of the CI\&C is shown in fig. 1 . The system currently provides process-control dataintegration and display services for twelve engineering subsystems and three NSTX diagnostics. Using networked $\mathrm{x}$ terminals, operators monitor all engineering subsystems and, if authorized, control them. Using CAMAC Input/Output (I/O) modules, the CI\&C uses EPICS to perform process control functions for the subsystems. Some subsystems use a Programmable Logic Controller (PLC). The PLC provides the bulk of process control logic and I/O. Through a communication interface, the CI\&C can centralize data and control of the subsystem. The CI\&C is also used to acquire and archive NSTX experimental data into the NSTX Data Management System [2].

\section{A. NSTX Application Software}

The EPICS NSTX-specific application software is presently comprised of 135 EPICS display pages, 1,500 I/O points, and 7,000 EPICS records. A record resides in the IOC's runtime database and is used to describe an $\mathrm{I} / \mathrm{O}$ point or a data processing function. Note that EPICS is primarily designed for continuous process control applications. To support the special needs of NSTX's 'pulsed' operations, twenty ' $C$ ' programs and fifteen unix-scripts were written. These programs interface EPICS with other software that is used on NSTX, such as MDSplus data management and IPCS [3] interprocess messaging software.

\section{OPERATIONAL EXPERIENCE}

The sections below describe our experiences pertaining to several important topics that affect system operations.

\section{A. Reliability}

EPICS has operated very reliably in the two and one-half years since NSTX achieved first-plasma. EPICS hardware or software has not been the cause of any significant interruption to plasma operations. The excellent reliability can be attributed to several factors. By far the most influential factor is the reliability of the collaboration-supplied EPICS software. The version of EPICS that is in use at NSTX has been extensively tested and used for experiments at laboratories that have a lot of EPICS expertise. The reliability of the commercial operating systems, including VxWorks and Solaris, contribute towards this achievement.

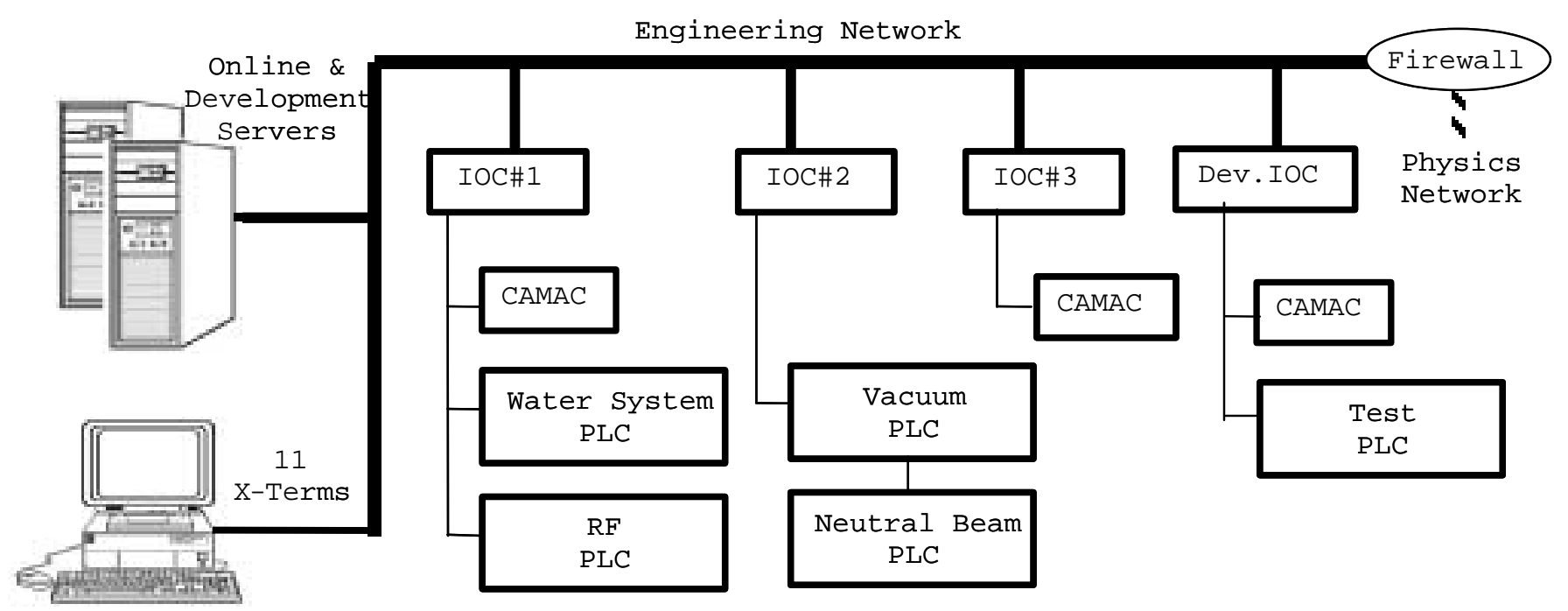

Fig. 1 Simplified Block Diagram of EPICS -based NSTX CI\&C

* Work performed under the auspices of the US DOE by Princeton Plasma Physics Laboratory under Contract No. DE-AC02-76-CH0-3073. 
Another factor that contributes to the success of EPICS at NSTX is the system engineering practices and procedures that are used. A high reliance on software testing and configuration control are two of the best examples of this. Spare computing and I/O hardware has been configured as an EPICS development and test system. The development system permits new software to be evaluated prior to being brought online. Frequent NSTX maintenance weeks are used to test new software prior to the resumption of NSTX operations. Portions of the EPICS software are on a Critical Software list. Engineering procedures such as design reviews and test procedures are used to control changes to this software.

\section{B. Maintainability}

Required Labor: Notwithstanding the generous intellectual support from the EPICS collaboration, the NSTX EPICS computing and I/O hardware, and software, is supported by only two engineers, who devote $75 \%$ of their time to EPICS. Occasional assistance from unix system administrators, the network group, and technicians is also required. With this modest level of support, EPICS can be said to be a laborefficient control system. This is a notable fact because the total lifetime cost of a control system is often dominated by software-labor costs.

External Costs: EPICS is generally 'open' and free software, but most EPICS configurations use commercial, licensed software. Under existing PPPL subcontracts, NSTX has elected to purchase annual software support plans. This amounts to about US $\$ 5,000$ and includes Tornado/VxWorks, IDL, and Solaris. Note that there is ongoing work within the EPICS community to reduce these modest costs by eliminating the need for these commercial products.

\section{Lessons Learned}

While the overall experience with EPICS has been excellent, there are two design decisions that have marginally reduced the reliability and maintainability of the system. Owing to the high modularity of the EPICS software and hardware, these areas can readily be improved upon if the need arises.

Code Readability: One of the most significant software maintenance challenges has been in applications where the engineering subsystem has diverse operating modes or has real-time control requirements. Standard EPICS provides the flexibility to fulfill a control function in a variety of ways. The best method is usually to use the EPICS standard runtime database. This uses the core EPICS software and development utilities, which are very reliable. If there are complex control functions, a Sequencer program (a C-like program that runs on the IOC) can be written. Some systems, such as the NSTX Gas Injection and the Central Clock use a solution that is a hybrid that uses both methods. While this approach is 'normal' in the EPICS community and will produce a working system, testing and software changes can be difficult if the functional divisions (database and sequencer program) are not clearly made during the initial software design.

X-Terminals: EPICS display applications are designed to operate in an X-windows environment. One of the least reliable components of the NSTX EPICS system has been the $\mathrm{x}$ terminals. There have been three monitor (hardware) failures and numerous 'soft' failures. The latter type of failures include the inability to open additional $\mathrm{x}$-windows, the necessity to open applications in a specified order to avoid color-table limitations, the need for an external font-server computer, and the need for an elaborate print serving configuration. After extensive investigation and memory upgrades, the problems have not been eradicated. In the future, the preference will be to use a PC with an $\mathrm{x}$-terminal emulator program.

\section{EPICS IMPROVEMENTS}

The CI\&C has undergone enhancements and added new engineering subsystems over the past two years. This section will describe notable achievements.

\section{A. Engineering Subsystems}

New Engineering subsystems that were interfaced with CI\&C include the NSTX Thermocouple system, the Lower Dome Gas Injection system, the Diagnostic Gas Injection system, and the Neutral Beam Injection system. All of these systems use legacy CAMAC I/O and the gas and neutral beam systems have a subsystem PLC. In addition, several NSTX diagnostics are being provided with NSTX machine status via EPICS.

\section{B. EPICS Tools}

The functionality of CI\&C has recently been expanded to provide two new functions, a diagnostic data interface and data archiving. A data interface was needed between EPICS and non-EPICS (i.e. diagnostics) control systems. The EPICS collaboration has produced a variety of these, but there has been no experience in using them at NSTX. Since the number of points was small and the need immediate, a simple method that uses an ASCII file was implemented. Several times per minute, a list of EPICS record names and their current values are written to the ASCII file on an 'exported' disk. Programs on other non-EPICS computers can read the file to determine the state of the I/O points. This method is slow and requires frequent disk access, and will likely be improved upon.

Another significant addition to the CI\&C was the capability to directly archive data into the MDSplus-based NSTX Data Management system. Until recently, CI\&C sent data to programs on the MDSplus server through data files and IPCS messages. Software maintenance was cumbersome because coordinated programming changes were required on both the EPICS side and the MDSplus server side whenever a new signal was added. With MDSplus-writing capability, EPICS

\footnotetext{
* Work performed under the auspices of the US DOE by Princeton Plasma Physics Laboratory under Contract No. DE-AC02-76-CH0-3073.
} 
programmers have autonomous control over the data that is archived. The new capability was implemented by installing MDSplus client software for unix on the CI\&C computers. A combination of 'IDL' and ' $C$ ' programs are used to interface MDSplus client software with EPICS.

\section{EPICS Upgrade}

One of the benefits of the EPICS collaboration is the excellent technical support that is available. As with most software, the knowledge for older version is lost over a period of time. So, it is important that NSTX continue to use commonly-used EPICS software. This necessitates that the EPICS software be periodically upgraded, about once per year. The use of new releases is a low risk endeavor because of the extensive testing done by the collaboration. Nevertheless, thorough testing at NSTX is required to ensure that all applications continue to work with the new software.

Earlier this year a major accomplishment was achieved when an upgraded version of EPICS was installed and used to for the most recent run period. This is a significant milestone because the installation of the upgrade was performed without direct assistance from the collaboration. The upgrade was a complete installation, from unformatted disks and out-of-thebox VME CPUs to a fully functional control system. In addition to upgrading the base EPICS release, upgrades were applied to the Solaris operating system and several EPICS software tools (extensions). The entire process was thoroughly documented in a series of procedures to help with subsequent upgrades. In addition, a test methodology for all NSTX applications was established and successfully used.

\section{FUTURE PLANS}

There are two new PLC-based NSTX Engineering Subsystems that are in the planning stages, the Pellet Injector and the Ground Fault Detection system. Both of the PLC's are expected to be in the Allen-Bradley PLC-5 family, so integration with EPICS should be straightforward. The current implementation of EPICS-to-PLC5 communications is slow, and the addition of new signals requires alterations to the PLC's internal block transfer timing and the EPICS communication software. A revised communication methodology will be explored in the near future to improve upon these two areas.

EPICS is a continually evolving system. An active collaboration is continuing to focus on reducing the cost of building and maintaining a control system through improvements in the areas of software portability and the elimination of single-sourced software and hardware products. To avoid technological obsolescence NSTX must keep up with mainstream EPICS developments. Our plans to remain current as well as evaluate and explore alternate, lower-cost, modern hardware and software platforms will be described.

The EPICS release in use on NSTX is two versions behind the current release. One of the reasons for this is that the most recent release requires the (Wind River Systems) Tornado II software. The current plan is to install Tornado II, the latest EPICS release, and port and test all applications on the CI\&C EPICS development system. The processes and procedures that were successfully used during the Winter 2001 EPICS upgrade will be used for this EPICS upgrade. Exporting EPICS data to NSTX diagnostics was described earlier. This is an area that needs improvement. The current methods are very slow and are relatively difficult to maintain. One solution is to provide an EPICS export-server, which will have access to the EPICS CA servers on the Engineering network, and provide convenient software interfaces for the applications running on non-EPICS systems.

To ensure the longevity of the NSTX CI\&C, alternative, lower-cost, modern hardware and software platforms for EPICS must be explored. One of the most promising industrial $\mathrm{I} / \mathrm{O}$ platforms is CompactPCI [4]. The system architecture is similar to VME, but can leverage upon the worldwide popularity of the PCI bus. The prevalence of PCI technology in the PC marketplace promises strong support and longevity for the bus. The first EPICS development project for NSTX that is focused on the use of lower-cost I/O technology is to get EPICS running on non-VME CPUs. This includes a desktop PC and a CompactPCI CPU. Multiple operating systems will be investigated, such as VxWorks, Windows2000, Linux, and Linux with real-time extensions. A more significant challenge is in developing software to interface analog, digital, and timing I/O boards with the EPICS database.

\section{CONCLUSION}

The EPICS-based Central Instrumentation and Control System has performed very well in its initial two years at NSTX. The system has demonstrated highly availability and can be maintained with a small programming staff. In the near future, the system will be expanded to accommodate new engineering subsystems, incorporate additional EPICS software capability to enhance the effectiveness of the operators, and begin to explore the use of new technologies, such as CompactPCI.

\section{REFERENCES}

[1] P. Sichta, J. Dong, 'The NSTX Central Instrumentation and Control System,' 18th Symposium on Fusion Engineering, Albuquerque, NM (1999).

[2] W. Davis, et al, 'The use of MDSplus on NSTX at PPPL,' $3^{\text {rd }}$ IAEA TCM on Control, Data Acquisition, and Remote Participation for Fusion Research, Padova, Italy (2001).

[3] G.G. Preckshot, D.N. Butner, "A Simple and Efficient Interprocess Communication System for Actually Using a Laboratory Computer Network," IEEE Trans. Nuclear Science, NS-34, 1987, p. 858.

[4] CompactPCI Core Specification, PICMG 2.0 R3.0, available from the PCI Industrial Computer Manufacturers Group, Wakefield, MA. 


\section{External Distribution}

Plasma Research Laboratory, Australian National University, Australia

Professor I.R. J ones, Flinders University, Australia

Professor J oão Canalle, Instituto de Fisica DEQ/IF - UERJ , Brazil

Mr. Gerson O. Ludwig, Instituto Nacional de Pesquisas, Brazil

Dr. P.H. Sakanaka, Instituto Fisica, Brazil

The Librarian, Culham Laboratory, England

Library, R61, Rutherford Appleton Laboratory, England

Mrs. S.A. Hutchinson, JET Library, England

Professor M.N. Bussac, Ecole Polytechnique, France

Librarian, Max-Planck-Institut für Plasmaphysik, Germany

J olan Moldvai, Reports Library, MTA KFKI-ATKI, Hungary

Dr. P. Kaw, Institute for Plasma Research, India

Ms. P.J . Pathak, Librarian, Insitute for Plasma Research, India

Ms. Clelia De Palo, Associazione EURATOM-ENEA, I taly

Dr. G. Grosso, Instituto di Fisica del Plasma, Italy

Librarian, Naka Fusion Research Establishment, J AERI, J apan

Library, Plasma Physics Laboratory, Kyoto University, J apan

Research Information Center, National Institute for Fusion Science, J apan

Dr. O. Mitarai, Kyushu Tokai University, J apan

Library, Academia Sinica, Institute of Plasma Physics, People's Republic of China

Shih-Tung Tsai, Institute of Physics, Chinese Academy of Sciences, People's Republic of China

Dr. S. Mirnov, TRINITI, Troitsk, Russian Federation, Russia

Dr. V.S. Strelkov, Kurchatov Institute, Russian Federation, Russia

Professor Peter Lukac, Katedra Fyziky Plazmy MFF UK, Mlynska dolina F-2, Komenskeho Univerzita, SK-842 15 Bratislava, Slovakia

Dr. G.S. Lee, Korea Basic Science Institute, South Korea

Mr. Dennis Bruggink, Fusion Library, University of Wisconsin, USA

Institute for Plasma Research, University of Maryland, USA

Librarian, Fusion Energy Division, Oak Ridge National Laboratory, USA

Librarian, Institute of Fusion Studies, University of Texas, USA

Librarian, Magnetic Fusion Program, Lawrence Livermore National Laboratory, USA

Library, General Atomics, USA

Plasma Physics Group, Fusion Energy Research Program, University of California at San Diego, USA

Plasma Physics Library, Columbia University, USA

Alkesh Punjabi, Center for Fusion Research and Training, Hampton University, USA

Dr. W.M. Stacey, Fusion Research Center, Georgia Institute of Technology, USA

Dr. J ohn Willis, U.S. Department of Energy, Office of Fusion Energy Sciences, USA

Mr. Paul H. Wright, Indianapolis, Indiana, USA 
The Princeton Plasma Physics Laboratory is operated by Princeton University under contract with the U.S. Department of Energy.

\author{
Information Services \\ Princeton Plasma Physics Laboratory \\ P.O. Box 451 \\ Princeton, NJ 08543
}

Phone: 609-243-2750

Fax: 609-243-2751

e-mail: pppl_info@pppl.gov

Internet Address: http://www.pppl.gov 